Open Access

\title{
The structure of ritual and the epistemological approach to ritual study
}

Qiao Wu

Correspondence:

wuqiaowuqiao@163.com Institute of Sociology, Chinese

Academy of Social Sciences, Room 1043 on 10th Floor, No. 5 Jian Guo

Men Nei Street, Beijing, China

\begin{abstract}
With cases collected from long-term fieldwork on two ethnic groups of China, the Flora-belt Dai and the Ao Yao, this paper analyzes predominant definitions of "ritual." It discusses such issues as ritual's technique versus the supernatural, the sacred versus the profane, symbol and metaphor, the non-Aristotelian definition and the operational definition in order to examine their generalities. The paper then presents a new point of view on ritual's structure and function through the angle of epistemology: as a human activity, ritual contains certain progressive meanings based on an ethnic group's exclusive cultural facts. Ritual functions as visualization and activation of these cultural facts. Presuming an intercommunity between informants and anthropologists, the paper offers the possibility of further study in anthropological ritual research.
\end{abstract}

Keywords: Ritual study, Epistemology, Flora-belt Dai, Ao Yao

\section{Background}

Ritual study has always been a major topic in anthropological research. Both the stealing of branches from the temple in The Golden Bough, written by anthropologists' predecessor James George Frazer, and the Kula ring described in Argonauts of the Western Pacific, which set standards for fieldwork, are classic examples of ritual study. Evans-Pritchard's Nuer and Clifford Geertz's Bali series are both significant works in their description and analysis of ritual. Scholars have observed that rituals and celebrations are occasions with concentrated expression of cultural meanings. The cultural meanings in rituals within 1 day may be richer than those in ordinary activities within 1 month, making ritual more promising in seeking of meaning. In recent years, monographs and essays with "ritual" as a keyword take up a great proportion of anthropological results. There are also academic journals that focus on ritual study. ${ }^{1}$

Although many distinguished scholars have contributed to ritual studies and much academic attention is paid to this field, a stable core concept is still lacking in academia as a whole. This essay discusses the definition of ritual and research approaches according to the main ritual theories through case studies of the Floral-belt Dai and the Ao Yao.

\section{Discussion}

\section{Distinguishing ritual's technicality and supernaturalism}

Before the cases are described, it is necessary to review the definition of ritual given by scholars. In the field of anthropology, renowned scholars have offered vastly different

(C) The Author(s). 2018 Open Access This article is distributed under the terms of the Creative Commons Attribution 4.0 International License (http://creativecommons.org/licenses/by/4.0/), which permits unrestricted use, distribution, and reproduction in any medium, provided you give appropriate credit to the original author(s) and the source, provide a link to the Creative Commons license, and indicate if changes were made. 
definitions of ritual. However, one consensus is widely accepted by scholars: that the mechanism and philosophy of ritual differ from other behaviors in daily life, i.e., it is both nontechnical and supernatural.

For example, Turner $(1967,19)$ writes in The Forest of Symbols that "by 'ritual' I mean prescribed formal behavior for occasions not given over to technological routine, having reference to beliefs in mystical beings or powers." Sir Leach $(2004,13)$ states in Systems of Highland Burma: A Study of Kachin Social Structure that "ritual denotes those aspects of prescribed formal behavior which have no direct technological consequence." van Beek defines ritual as "stable patterns of activity in which men address the supernatural." A Dutch scholar quotes the Journal of Royal Anthropological Institute (1951) that "ritual, like etiquette, is a formal mode of behavior recognized as correct, but unlike the latter it implies belief in the operation of supernatural agencies and forces" (Platvoet and Van Der Toorn 1995, 42-45).

It can be seen from the above that many renowned scholars believe the main difference between ritual and nonritual activities lies in the opposition between technicality and supernaturalism. Is it universal? Let us look at a field case.

On October 16, 2006 (the 25th day of the 8th lunar month), soon after I came to the colony of Floral-belt $\mathrm{Dai}^{2}$ to do my fieldwork, farmers began their autumn harvest for this year. My hosts in Broussonetia village, the couple Ayan and La'an, harvested rice in their fields throughout the day. This was their last batch of rice this year. After they finished reaping, they left the straw on the ridges of the fields to dry up. When they had harvested the paddies La'an selected several long and plump ears of grain. Having finished threshing, La'an went home, climbed into the barn in the back room on the second floor, and hung these ears on the hook hanging from the roof over the center of the barn. As La'an told me, the dried ears attached to the hook were harvested last year and this is where $\mathrm{p}^{\mathrm{i}} \mathrm{i} \mathrm{1}^{3}$ stays. An ear will be hitched and consecrated to $\mathrm{p}^{\mathrm{i}} \mathrm{i} 1$ after finishing the rice harvesting each year. Having hung the p'il, La'an set some cooked rice, a

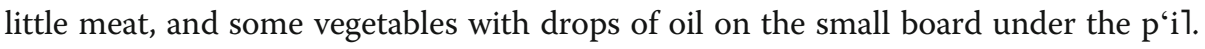

Ayan held part of the straw dried on the ridges of the field during harvest on the dry field, lit it, burned it into ashes, and covered it with a piece of plastic sheet in case it was washed away by rain. Several days later Ayan plowed and harrowed repeatedly, finished the preparation of a small seedling field, and began to plant seedlings. He evenly scattered seeds into the soft and leveled muddy bed. Afterward he brought the previously burned straw ashes and placed a thick layer on the seeds.

On February 17, 2007, Lunar New Year's Eve, La'an carried a fishing net with her family's clothes, a bottle of wine, a sickle, an egg, a box of meal, and a pair of wood strips. Holding these, La'an went to their small balcony, beginning to murmur and chant a rhyme. Her whole chant lasted for about half an hour; one part was like this: "heng ${ }^{4}$ of rice, may you stably come back meng after meng from thirty wide Heaven roads. Please come back once you hear my call. Come to the fields and do not be stolen by mice. Stay sound and do not get picked by birds. Come back, come back ... let me hook you back with the sickle and let you rest peacefully at home." After chanting, La'an swung the sickle on the ground three times and tossed the wood strips onto the earth until she was satisfied with the results, ${ }^{5}$ and finished. 
Several days later on February 22, the fourth day of the first lunar month, Broussonetia villagers began to work in the fields, which is called kaiyangmen. ${ }^{6}$ Ayan first went to their own cattle shed, dug out all the manure (i.e., a mixture of cattle dung, urine, and dirt) which had accumulated, broke it up with a hoe, carried it to the fields, and scattered it there. Then he soaked some urea grains in water and splashed them in the fields. Ayan told me it was "base fertilizer." After this application of fertilizer, Ayan plucked the seedlings that had grown higher than one-sixth of a meter from the seedling field, divided them into stacks, and inserted each into the field in rows. About one month after finishing the rice transplanting, Ayan applied fertilizer a second time. Then the couple went to the field and pulled out the weeds. Work on the early rice crop was then completed and we could wait for its growth and harvest.

The above passages depict the basic procedures of Floral-belt Dai's agricultural production, from threshing in the previous year to planting seedlings in the next year. Over the years, Floral-belt Dai have produced and lived in this way. According to the standards set by anthropologists mentioned above, the first paragraph of the case description is a ritual, the second is daily life and production, the third is another ritual, and the fourth returns to daily life and production. The burning of straw and applying fertilizer described in the second and fourth paragraphs are "technical" actions that are often seen, while offering sacrifices to p'i1 and calling hengs in the first and third paragraphs are typical "supernatural" activities.

Having observed the abovementioned activities in the field, I interviewed the natives. The interviewee told me that these activities have a common aim, i.e., to get a good harvest of rice. Floral-belt Dai explain that the aim of scattering straw ashes and manure is to make seedlings stronger. The sacrifice described in the second paragraph

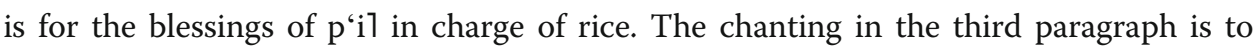
call back the dissipated heng of rice.

I did not fully grasp the logic of the above activities until I became more fluent in the Floral-belt Dai's language and understood their belief systems more fully. Floral-belt Dai believe all living things-humans, livestock, rice, wild animals, and plants-own hengs. The heng of a human looks like a human, cattle's hengs look like cattle, and grain's heng is just like an ear of grain. Although heng is generally invisible, ${ }^{7}$ human, livestock, and grain can be good only when the heng is adequate and healthy. If the heng is dissipated, one will be dispirited and ill, livestock will be feeble and less fertile, and seedlings will be weak and bring poor harvest. However, hengs are usually dissipated. That is why, activities are held regularly and irregularly to call hengs back. Only in this way can a good harvest of rice be ensured.

Besides heng, the Floral-belt Dai also have concepts of p'i1. Put simply, p'i1 are gods in charge of certain affairs. The $\mathrm{p}^{\mathrm{i}} \mathrm{i}$ l of grain are in charge of rice; $\mathrm{p}^{\mathrm{i}} \mathrm{i}$ h have an appearance just like humans and have the same emotions and needs as humans. Making a sacrifice to $\mathrm{p}$ ' $\mathrm{i} 7$ can make them happy. The general source of various living things' heng is the goddess Mimao Miwa and a couple of Serpent $\mathrm{p}^{\mathrm{i}} \mathrm{i} 1$ in heaven. By sacrificing to and pleasing $\mathrm{p}$ ' $\mathrm{i}$, more heng can be sent from heaven to humans, and people can look forward to good health, harvest, and livestock.

Besides the above-mentioned sacrifice to $\mathrm{p}^{\mathrm{i}} \mathrm{i} 1$ of grain held within the household, Floral-belt Dai have many other sacrifice activities held collectively by the whole village. For example, during the Sacrifice Ceremony once a year, Floral-belt Dai sacrifice pigs and cattle to the $\mathrm{p}^{\mathrm{i}} \mathrm{i} 1$ in charge of the village, and invite all the $\mathrm{p}^{\mathrm{i}} \mathrm{i} 1$ from every famous place to 
have a meal. These $\mathrm{p}^{\mathrm{i}} \mathrm{i} 1$ from elsewhere will $\operatorname{chant}^{8}$ in the voice of the head witch of the village, ${ }^{9}$ stating they have brought rice flowers (representing the heng of grain), the heng of cattle, the heng of pigs, and the heng of wild animals (the prey of Floral-belt Dai).

In the rite of the spirit descent of the "Moon Mistress," which is held once per several years, the function of heng and $\mathrm{p}^{\mathrm{i}} \mathrm{i}$ is more obvious. The beginning of the rite is calling the p'il. Women chant together: "The rice planted by earthly women grows badly so we are inviting $\mathrm{p}$ ' $\mathrm{i} 1$ of Moon Mistress to help." During the ritual women possessed by the $\mathrm{p}^{\mathrm{i}} \mathrm{i}$ i of the Moon Mistress jump and dance crazily deep into the night. On the day when the ritual comes to the end, people hold another feast to sacrifice to the $\mathrm{p}^{\mathrm{i}} \mathrm{i} 1$ of the Moon Mistress. It is believed that once the $\mathrm{p}$ ' $\mathrm{i}$ l of the Moon Mistress are pleased, they will bestow the heng of grain on the village and bring a good harvest to make the village rich.

When I asked the Floral-belt Dai why they hold the rite of spirit descent of the "Moon Mistress,"10 everybody told me it would make the fields and crops better. An old witch even told me, "Someone says if we dance in the rite of spirit descent of the 'Moon Mistress' planting rice won't require fertilizer." But she added, "I think fertilizer is still needed. It will just take less if we hold the rite."

It is not difficult to see that in the Floral-belt Dai's view, applying fertilizer, calling heng, and making a sacrifice to $\mathrm{p}$ 'il are the same, even complementary, acts. They do not see the former as "technique" or the latter as "supernatural," nor do they regard the former as "ordinary" or the latter as "mystical." Actually, the opposing words meaning "technique" and "supernatural" do not exist in the Floral-belt Dai's language. ${ }^{11}$ The word "Mo"12 is used for all the activities related to witch chanting, such as "reciting $M o$," "doing $M o$," and "telepathically communicating Mo." Only witches can undertake activities related to Mo. During Mo witches chant in a fairly fixed form for several hours or even days. Different from daily Dai, the language used in chanting is not known by ordinary people; they can neither speak nor understand it. Therefore, Floral-belt Dai's Mo defines a certain kind of special activity. However, Floral-belt Dai never classify sacrifice to the $\mathrm{p}^{\mathrm{i}} \mathrm{i} 1$ of grain or calling the heng of grain as Mo. These two activities do not need to be conducted by clergy ("specialists," as Turner calls them) such as witches. Any housewife ("laymen," as Turner calls them) is allowed and able to do it. There is no chanting in the sacrifice to the p'il of grain; when calling heng, chanting is needed but only for a very short time, with a casual content and in the daily Dai language that is known by all.

Are these two activities mystical? "Mystical" means "of hidden or esoteric meaning."13 However, in the Floral-belt Dai's view, sacrifice to the $\mathrm{p}$ ' $\mathrm{i}$ 1 of grain and calling the heng of grain are simple and clear acts, not esoteric at all. When I asked about the difficulty in these actions, a Floral-belt Dai told me that sacrifice to the p i $i$ of grain is like setting out wine and a meal for his own parents or other elders to feast on them, and calling the heng of grain is like calling chickens and ducks back home at dusk-"If one can speak, he or she can do it." ${ }^{14}$ Thus, the dichotomies of technique versus supernatural or apparent versus mystical are not distinguished in Floral-belt Dai's society.

Some researchers have already noted that these activities are the same from the natives' perspective. As Durkheim states in The Elementary Forms of the Religious Life, "for him [primitive], there is nothing strange in being able, by voice to gesture, to command the elements, hold up or accelerate the course of the stars, make the rain fall or stop it, and so on. The rites he uses to ensure the fertility of the soil or of the animal species that nourish him are no more irrational in his eyes than are, in our own eyes, the technical 
processes that our agronomists use for the same purpose. The forces he brings into play by these various means do not seem to him particularly mysterious" (Durkheim 1999, 30). The situation in the Floral-belt Dai's case conforms to Durkheim's argument.

Let us look at another example:

On February 10, 2013, the first day of the Lunar New Year, I came to Xiaguchen villiage where the Aoyao ${ }^{15}$ live, and lived in the home of a wizard, ${ }^{16}$ preparing to film their forthcoming ritual called "tiaoganwang." Just a few days after I arrived I got tonsillitis and had a terrible throat ache. The wizard Zhiqiang Pan came to see me and said he would treat me. He set a bowl with a little rice and meat before me, chanting and stroking my neck. Having chanted for ten minutes, Zhiqiang Pan held the rice and meat toward the road outside the village, poured it out, and came back. Then he asked me, "Are you better now?" I nodded. He said, "Soon you will get well."

The next day my throat was still swollen and ached. Another old wizard in the home, Zhensong Pan, said he would like to treat me. He climbed up the mountain and dug up a rootstock that I did not recognize, over two-thirds decimeter in length and as wide as an index finger. Zhensong Pan peeled the cortex with a knife and revealed the yellow core. He boiled a kettle of water and immersed the core in hot water until the juice became yellow. The wizard handed the yellow juice to me. I drank as he instructed, tasting the bitterness. The wizard said if I drank this juice for two days, I would be healed.

The two wizards used two methods to treat my throat ache. In the later interviews, I roughly made clear two sets of pathology theories. One wizard told me that everyone has 12 souls. Part of the souls may get lost in life, which makes people become ill. Losing souls usually happens when someone is haunted by spirits who want a sacrifice from humans. For example, I fell ill because when I passed by the mountain forest, one of my souls was absorbed by mountain spirits. The mountain spirits asked for a sacrifice, so the wizard's chanting sent the "troops" to negotiate with the spirits and offer them food, i.e., the meat and wine. This method is called "ransoming souls," which is quite common in the Aoyao's life.

However, drinking the yellow juice is a totally different pathology theory. This wizard said additionally that my throat swelled and ached because there was too much "heat" in my body, and this plant is "cold" in nature. When I took this cold medicine, the heat in my body would be counteracted and my throat ache would be healed. The wizard explained that every human body has the two natures of hot and cold. One will be healthy if he or she has the proper amount of each. If there is too much heat but too little cold, one will get a hot illness such as a swelling and aching throat, toothache, or skin ulcer. If there is too much cold and too little heat, one will get a cold illness such as a weak stomach, back pain, or some women's diseases. All animals and plants have cold and hot natures. One treats a hot illness with cold plants and a cold illness with hot ones. ${ }^{17}$

When I asked which of these two different pathology theories and treatment methods was the right one, the wizard told me there is no right or wrong, better or worse; both methods are useful. When Yao fall ill in daily life, both methods are used in treatment. Furthermore, in my observation, both wizards appeared calm, with a steady tone and 
relaxed movements. When talking about the outcome of the treatment, they were equally confident. I cannot determine which one is more mystical or serious, nor do I recognize a distinction between technique and supernatural.

The above analysis shows that the opposition between technique and supernatural or mystical is not a universal standard to distinguish ritual and nonritual. The subject of culture, i.e., natives, does not generally adopt such a classification system. If we regard it as a classification used not by the target of research but by the researchers themselves, the prerequisites of this classification lie in the definitions of both "technique" and "supernatural." However, I have not found any such definitions used by those who carry this binary opposition.

\section{The sacredness and taboo of ritual: an analysis}

Anthropologists have another widely accepted definition of ritual: the essential difference between ritual and nonritual activities is that other human activities are ordinary and profane, while rituals are sacred and serious. For example, in The Elementary Forms of the Religious Life Durkheim $(1999,49)$ wrote that "rites are rules of conduct that prescribe how man must conduct himself with sacred things." Geertz argues in The Interpretation of Culture: "Ritual is consecrated behavior [in which the] conviction that religious conceptions are veridical and that religious directives are sound is somehow generated. [Ritual is] some sort of ceremonial form [in which] the moods and motivations which sacred symbols induce in men and the general conceptions of the order of existence which they formulate for men meet and reinforce one another" (Geertz 1973, 112-14).

The analysis method of sacred versus profane devised by Durkheim has had enormous influence on anthropologists. Later works like Mircea Eliade's Sacred and Profane develop it further. Sacred versus profane has become not only the boundary between religion and other social facts but also the universal classification standard of all cultural products of humans, becoming a paradigm of study. As far as I have seen, the mysticality of ritual is hard to perceive in some ethnic groups:

In February 2013, I went to Dayao Mountain, Jinxiu County, Guangxi Province with a research team. We filmed a large collective sacrifice ritual called "tiaoganwang." On May 3 I returned to Dayao Mountain, played the film for the presiders and performers including wizards, temple attendants, and dancers and asked them to explain the meaning of every procedure to us. In the film when a temple attendant led the ranks inviting spirits to the temple, he stood before the temple, hands spreading outward from his chest as if he were opening the gate, and chanted quietly for a while. A wizard told me this was "opening the temple gate." I asked the temple attendant what he was chanting quietly. He said he was telling the spirits in the temple, "We are inviting and carrying you to the village to entertain you with song, dancing, and a feast," just what you would say when you visit someone's family. I asked him again, "Is this quiet chant magic? Is it sacred?"18 Hearing my question, the temple attendant and wizards all laughed. After laughing for a while, the wizard said, "If the chant is quiet and no one else hears it, it is sacred. If the chant is loud and others hear it, it is all daily words."

Let us see another example from the Floral-belt $\mathrm{Dai}^{19}$ : 
On February 8th, 2007, the head witch of Broussonetia village, Meiying Zhao, held a "gaihuo" ritual for the previously deceased old villager Mingzheng Bai. From 9:00 a.m. till 5:00 p.m., Meiying Zhao sat up straight and concentrated on chanting in the principal room of the Bais' first floor. The old and middle-aged women from the entire village sat around the room, absorbed in listening to her chanting. Zhao's husband, Zhonghua Yang, sat and drank with the household and guests in the outer room. Yang had always been a drunkard and a notorious womanizer. Feeling tipsy, he began to flirt with the woman guest beside him and sing a ditty. I was standing across the threshold and recording Meiying Zhao's chant when she suddenly exclaimed during her rhythmic long sentences: "Taił xa」 mot! Va hei」 tait lau」 pjen va」 lau」 jo! " All the women around the room laughed loudly. I had not learned Dai's language yet and did not understand its meaning, but I could recognize from her tone and listeners' expressions that it was definitely not part of the chant. As expected, I was told she was excoriating her husband: "Damn you, old man! Don't get drunk and be silly again!" After she said these words as an offended wife, her husband got quiet and she went on chanting as a witch.

In my fieldwork, I observed that there is no distinct boundary between sacredness and profanity in the Aoyao's ritual. Floral-belt Dai witches often conduct other social affairs during a ritual, just as Meiying Zhao suspended her chanting to excoriate her presumptuous husband. They bring a religious ritual to a halt and deal with something else, just like hearing water boiling during spinning and delaying the spinning to put vegetables into the pot. It is a natural and rational action for both the witch herself and her listeners. According to Durkheim's (1999) understanding of "sacred," chanting for $\mathrm{p}$ ' $\mathrm{i} 1$ is sacred and protected by taboo, whereas supervision on husband is the object to supervise that must be kept distant from sacred things. However, in the above two field cases, sacred affairs are not sublime, serious, and inviolable acts and profane activities during them are not taboo. In fact, in the Floral-belt Dai's case, it is difficult to distinguish ritual affairs from daily life; observers from other cultures may see them without recognizing them as rituals. ${ }^{20}$

There are many cases like this in other ethnic groups such as the Moso and Daur. Generally speaking, to these natives, rituals are part of rather than in opposition to daily life. The dichotomy of sacredness and profanity does not apply to them. From this perspective, this dichotomy cannot be used as a core element in defining ritual.

\section{The symbol and metaphor of ritual}

Many anthropologists believe the essential characteristic of ritual is that they are symbol-centered human activities. For example, Firth $(1951,222)$ argues, "Ritual is a kind of patterned activity oriented towards the control of human affairs, primarily symbolic in character with a non-empirical referent, and as a rule socially sanctioned." Tambiah observes, "Ritual is a culturally constructed system of symbolic communication. It is constituted of patterned and ordered sequences of words and acts, often expressed in multiple media" (Tambiah 1979, 119). Bocock (1974, 37) writes, "Ritual is the symbolic use of bodily movement and gesture in a social context to express and articulate meaning." Delattre $(1978,282)$ states, "Ritual is those carefully rehearsed symbolic motions and gestures." Kertzer defines ritual as "symbolic behavior that is socially standardized and repetitive. ... Ritual action has a formal quality to it. It follows 
highly structured, standardized sequences and is often enacted at certain places and times that are themselves endowed with special symbolic meaning" (Kertzer 1988, 9).

Since the keyword "symbol" appears repeatedly in many researchers' definitions, it is necessary to determine what it means. Semantic definitions for "symbol" are "a sign, shape or object which is used to represent something else" (Cambridge Advanced Learners Dictionary); or "a person, an object, an event, etc. that represents a more general quality or situation" (Oxford Advanced Learner's Dictionary). In anthropology many renowned works, from Turner's Dramas, Fields and Metaphors ${ }^{21}$ to Geertz's The Interpretation of Culture, use the term "symbol." Furthermore, they use "symbol" in its semantic meaning. To put it simply, if people use A to represent B and the connection between A and B is socially acquired, then A can be deemed to be B's symbol. Indeed, many rituals contain symbols and metaphors. In Floral-belt Dai and Aoyao rituals, we find many examples underpinning this opinion. Natives are experts at using metaphors. Anthropologists are aware of their ability to pick out "abstract attributes" from concrete affairs.

In spring 2007 I had lived with and conducted fieldwork in the Floral-belt Dai area for three months. During this period I became aware that according to traditional funeral customs, a grieving family should fire a musket three times when an elder passes away. The "xiaozi," i.e., dutiful son, would wear white kapok $^{22}$ clothes and a white kerchief. Daughters and sons-in-law who had married and moved out of the home should lead an ox and come back to grieve. The sons and nephews of the deceased would tie a long knife over their waists when they carried the coffin outside. On February 3, an old man named Zhengming Bai in Broussonetia village passed away. I went to his funeral, but what I saw was quite different from what I expected. The grieving family did not fire a musket but instead set off firecrackers when the elder died. The mourning attire worn by the xiaozi was a doctor's white coat borrowed from a township clinic. The daughter and son-in-law did not bring an ox; they just borrowed a calf from the neighbor of the deceased and led it to the xiaozi, who immediately returned it to the neighbor. The eldest son did not tie a traditional long knife at his waist; it was a plastic sword taken from his child's toy Transformers.

Afterward I interviewed the family. They told me that firing a musket is intended to inform neighbors of the grievous news. Since the government had previously banned firearms and all the muskets taken away, they changed to firecrackers, whose deafening sound would inform everyone that someone had passed away. In the past the xiaozi wore mourning attire woven from kapok because kapok is white, the color that represents grieving. It is now very hard to find handmade kapok mourning attire since people usually buy ready-made clothes from the market. Therefore a doctor's white coat is used instead. Only the white color matters. Married daughters and their husbands should lead an ox to a parent's funeral because an ox is Floral-belt Dai's highest-ranking gift, and thus represents the close, highest-ranking relationship between daughters and their parents. However, Bai's daughter married a Han and moved to faraway Zhejiang Province. Although she hurried back to the funeral on hearing the grievous news, she could not bring an ox with her, so she just borrowed the calf to show her respect. As is funeral custom, sons and sons-in-law of the deceased tie long knives to their waists because brambles grow along the way the heng of the deceased is sent to the goddess in the heaven. The men of the grieving family are responsible for slashing paths for the deceased with the long knives. Today long knives are hard to 
acquire, so they are replaced with plastic toys. Since slashing a path through brambles only appears in the witch chanting, plastic toy knives are sufficient.

To present another example:

On February 17, 2013, I noticed that when I was filming the "tiaoganwang" ritual apprentices tied a rope as high as chest around the "sacred platform," under the wizard's direction. Many red plastic bags hung on the rope. I asked the wizard what this meant. The wizard told me the area enclosed by the rope was a "sacred shed" where women are not allowed and the entering men had to first wash their hands and faces with "five-dragon water." I asked further why the plastic bags were hung. The wizard said red silk fabric was previously hung but silk fabric is now hard to find, so they used the ubiquitous plastic bags instead. Red is the color of spirit. The bags can represent the meaning only if they are red, and the spirits will not take offense.

As can be seen from the above cases, such metaphoric connections have been established among the two ethnic groups of Floral-belt Dai and Aoyao: white grievance and red sacred. Furthermore, they effortlessly abstract the two attributes, i.e., white and red, from concrete objects (kapok clothes and silk fabric) when actually performing. When it is necessary, they give up the actual objects and use their attributes only. Such examples are also ubiquitous among other ethnic groups I researched.

The cases of the Floral-belt Dai calling heng and the Aoyao treating ailments with bitter juice raise queries about the universality of symbols. There is no trace of symbol or metaphor in the abovementioned Floral-belt Dai calling the heng of grain. Calling heng, as explained by the Floral-belt Dai, is calling the scattering heng back. It is the same with housewives calling grazing geese and chickens back home at dusk ${ }^{23}$; "We just coax it back." ${ }^{24}$ None of the props they use, such as lunchboxes, sickles, wine, water, or wood strips for telling fortunes, refer to heng. Rice in a lunchbox and wine in a bottle are prepared for heng that is called back; a sickle is to hook heng back; dropping wood strips is to see whether heng has been called back already. That is, during the activities of calling the heng of grain, people's calls directly work on heng. There are no symbols here since there is no signifier or signified. It is similar with the Aoyao using bitter juice to treat an illness since bitter juice acts directly on a patient's hot disease. According to the Aoyao's explanation, cold medicines are usually bitter, but "bitter" is not equivalent to "cold."

However, from the traditional anthropological perspective, it is hard to say that the Floral-belt Dai's calling heng and the Aoyao's treating hot disease are not rituals. These two activities do not include symbolic metaphors or correspondence of signifier and signified. The action works directly on its recipient. In light of these two cases, though symbols and metaphors exist in many rituals they are not universal.

\section{Ritual's non-Aristotelian definition and operational definition}

In addition to the discussions among classic anthropologists, ritual researchers of the latest generation provide a new definition from a new point of view, which is worth probing. In 2006 Jan A.M. Snoek, a Dutch scholar, published an essay titled "Defining 'Rituals"' and proposed that ritual should be given a non-Aristotelian definition, i.e., so-called fuzzy sets and polythetic classes. Traditional Aristotelian classes are "based on only discrete characteristics." In other words, each member of the class must possess 
these characteristics. The reverse should also be true: only something with such characteristics can be included in such a class. Therefore, these characteristics and classes are "definitions." However, according to the author of Defining "Rituals," a class is "polythetic" if and only if "(A) each member of the class has a large but unspecified number of a set of characteristics occurring in the class as a whole, (B) each of those characteristics is possessed by a large number of those members, and (if fully polythetic) (C) no one of those characteristics is possessed by every member of the class." ${ }^{25}$ In the latter part of this essay, Snoek lists 21 common characteristics of rituals after he reviews the large number of definitions and characteristics put forward by scholars. ${ }^{26}$ According to the author, an activity is a ritual if it has some or most of these 21 characteristics. This way of creating a definition is indeed inspiring. It has broader applicability but also obvious limitations, that is, it cannot facilitate interaction within the research community.

What is the aim of definitions in the fields of social science? A definition is for study. It is not difficult to understand that if we want to make a phenomenon clear and focus on it, we have to draw its boundary against other various human activities. Moreover, only when a basic definition is given and is generally accepted by a discipline can effective discussions among different researchers and knowledge accumulation be possible, which is essential for the growth of human knowledge. This is difficult if the definition of "polythetic classes" is used. When researchers publish and exchange opinions within one academic community such as anthropology, they will actually find it impossible to engage in a dialog since the signified are entirely different though the same terminology (signifier) is used. Similarly, accumulation from prior and later generations of anthropologists will be also impossible if such definitions are used.

As we all know, if a concept (definition) or a theory is so loose that it can contain everything, it loses the point-"If it is everything, then it is nothing." But if it is too narrow and not abstract enough to gain a certain degree of universality, it cannot be called a theory-"Physical phenomena do not have comparability." All good theories are on the best equilibrium point between two extremes. A definition needs to be both abstract and operational. An "operational" definition is a universal practice in current social science. It must have a boundary and be clearly measurable.

Examples of operational definitions are not rare in the social sciences except for anthropology. For instance, international law's rules about territorial waters still adopt the standard of the ocean waters within 12 sea miles of the shoreline. Such a highly operational definition comes from another simple one: territorial waters are within the range of cannons on the shore. This definition looks autocratic but actually builds on a clear and unemotional academic and theoretical basis: territory is the domain that can be controlled by state power. ${ }^{27}$

It is not the content of the definition but the way to create it that deserves anthropologists' attention. If we can establish a measurable and operational definition for ritual on a clear and simple theoretic basis, it will obviously contribute to academic accumulation and development.

\section{New reflections on ritual structure and research perspectives}

After reviewing and analyzing all the above elements of ritual, it seems that a unified model of ritual is still not determined. In fact, some anthropologists believe it is 
impossible to establish a universal definition of ritual. However, anthropologists can always effortlessly differentiate rituals from other activities in the field and pay attention to them. Moreover, from the anthropologists of early days like Fraser and Morgan, to later scholars like Leach and Turner, to a new generation such as Muggler, researchers are never afraid of using the term "ritual" in their ethnography. For any ethnic group of any region being researched, ritual is real existence and a real research object. How is it recognized consciously or unconsciously?

If we are able to conduct anthropological research into anthropological field study, that is, observing anthropologists who observe others, perhaps we can answer that question as an observer. The terminology of former generations of scholars- "technique," "mystical," "direct," "literal," "implicit," and so on-are from the anthropologists' perspective rather than that of the natives. A commonality is not set up between the two subjects, i.e., researchers and informants.

Anthropologists always generate and utilize concepts as analytic apparatus. They do not have to do this according to concepts of the natives, nor must they do this with the consent of the informants. However, from the perspective of epistemology, anthropologists gain their concepts in the same way that natives do, so both have the probability of sharing concepts. If they do not, and if the concepts created by the anthropologists are proven to have no counterparts in many native societies' categories, then anthropologists are obliged to certify the legality and generality of their concepts. Otherwise, they face the famous subversive critique that David Schneider made regarding some stereotyped concepts: "Kinship', like totemism, the matrilineal complex and matriarchy, is a non-subject since it does not exist in any culture known to man," and "kinship' is an artifact of the anthropologists' analytic apparatus and has no concrete counterpart in the cultures of any of the societies we studied" $(1972,59)$.

Another consensus found in anthropologists who defined ritual was that they focused on religious rituals above all. That is undoubtedly because they conducted their research on classic objects of anthropology, i.e., pre-industrialized societies in which almost all rituals, despite their goals in politics, economy, or kinship, are related to religion or contain religious elements. This symbiosis confuses the above definitions of ritual with those of religion. However, we can see that not all rituals are religious. Especially in modern societies, fewer and fewer rituals involve religious elements. An integrated definition of ritual should include pre-industrialized and industrialized societies, as well as religious and profane life. In other words, only when we abstract the common features of both religious and profane rituals in both traditional and modern societies do we find the essence of ritual.

In my opinion, the point of rituals from the anthropological perspective is that they are human activities that carry some meanings. Such meanings are exclusive to an ethnic group. In other words, for an observer from another culture (i.e., an anthropologist in the field), such meanings will not be fully understood without in-depth interviews. To put it plainly, when fieldwork is conducted in a society of others, the activities you do not understand are rituals.

This definition must be further qualified. Let us analyze it with another case of the Floral-belt Dai:

On April 26, 2007, I followed Zhenggui Dao, an elder in Xinzhai village, and saw the Floral-belt Dai's skill in hunting wasps. ${ }^{28}$ 
Before setting off that morning, Zhenggui Dao first brought a basket of rice to Meizhen Bai's home, which is in the same village, asking her to call heng for him. Meizhen Bai is an experienced witch who had called heng for many people. Just as usual, Meizhen Bai brought wine, rice, a sickle, and a pair of strips to the small balcony and chanted there for about half an hour. Then she dropped the strips and swished the sickle on the ground, finishing her job. Afterward Bai explained that what she chanted was not about Dao's heng but calling the heng of the quarry, i.e., wasps. Thus the wasps would flourish and Dao would get the quarry that he deserved. Zhenggui Dao was not there when Meizhen Bai was chanting. He handed the rice to Bai, told her what he wanted, and then left. Bai did the chanting alone in her home. ${ }^{29}$

After Dao left Bai's home, he led me up a mountain road for an hour, to a thick forest in the Ailao piedmont. He had seen wasps here before but had never found the hive. This time Dao caught a fat cricket, pinched off its head to reveal the meat in the abdomen, and tied it to a twig. We waited nearby. Soon a large wasp flew here, buzzing and descending on the dead cricket to eat it. Then Dao took out a piece of white duck down, which was as big as a little finger. Afterward he took out a thread, tying one end to the duck down. He made a loose knot with the other end, carefully passed it over the eating wasp's tail to its waist and gently pulled the thread to secure it. The wasp was still eating the cricket as if it wasn't disturbed. After eating a while, it began to fly again. Dao instructed me to run after the wasp. We followed the down as the wasp zigzagged through the forest for several minutes. In the end it landed on a large tree. Searching up the trunk, we found a dark brown nest as big as a football, three meters high on the trunk.

Having found the nest, Dao did not rush to retrieve it. He swung the knife and cut down a branch of a tree beside it. The branch was as long as an arm. Dao hung it downward on the branch beside the wasp nest, secured it to ensure that it would not fall down, and then he and I left for home.

Two months later the early rice in Gasa basin had all been reaped and the straw was already dried. One day Zhenggui Dao led me to the forest again. This time he first tied a large bunch of dried straw to the tip of a long bamboo pole. When we arrived at the nest we saw the branch that had been previously cut down was already dry but still hung there. Zhenggui Dao set fire to both the straw and the branch. The flames were so strong that it formed a huge one-meter-square fireball. Dao poked this long torch under the nest, and the wasps were all burned to death and fell down to the earth, crackling and smoking. After the torch went out, Dao climbed up the tree and cut the nest down with a knife. He cut open the burned comb with its layers of sieve like nests. There was a white and fat wasp larva as large as a little finger in almost every hole. Some pupated into light yellow pupae but did not emerge from the pupal case. Dao weighed it and told me happily that he had gained two or three catties of wasp "meat." Back home that evening Dao fried the wasp larva and cooked a crisp golden dish. The grubs, eggs, and Chinese chive were also boiled into a full pot. We had a very good meal with self-brewed rice wine.

As an observer of this hunt, I had more than one question. First, I did not understand why an old grandmother should be asked to chant; second, I did not know why Dao tied a headless cricket to a branch; third, I had no idea what it meant to tie white duck down to the waist of a wasp; and finally, I was not sure why Dao cut a branch, hung it 
downward beside the nest, and came back after a long time to burn the wasps and retrieve the nest.

In the interview, Dao answered every question. His recent hunting had not been productive because the heng was not enough, so he asked the old woman Bai to chant and call heng. When the heng of quarries were called, his gain would be better. Pinching off the cricket's head was to spread the smell of its bowels and attract wasps. Tying the cricket with a thread was to fix the bait, otherwise the wasps would fetch the cricket and the hunters would have no time to react. Tying the down to the waist of the wasp would make the wasp fly more slowly back to the nest so that the hunters would be able to catch up. Moreover, the white feather moving against the background of the dark thick forest and streams would make it easier for hunters to track it. Since a wasp nest was always built concealed in high trees, this was the only way we could find it. When we found the nest it was not the right time to retrieve it. In summer and autumn the number of larvae inside the honeycomb was at the maximum and their meat was plump. Cutting a branch and hanging it downward was to show the nest already had an owner so that others who saw it later would not burn it and claim it. The first person to find it would be able to rest assured and wait to get the nest when the larvae were best in flavor.

Let us analyze this explanation by the Floral-belt Dai. For the above fourth question, the Floral-belt Dai said a branch looked like a palm and fingers while the downward branch was like a hand "holding" something, meaning someone owned it. This is obviously a typical example of using a symbol. Here the signifier is a downward branch and the signified is the ownership. It has this meaning not only when catching wasps but also in other cases. For example, according to Floral-belt Dai tradition, when a passerby temporarily puts a package on the roadside with a cut branch on it, it means that it has an owner and is not abandoned so others will not take it away. Such a corresponding relationship between the signifier and signified is repeatable behavior that is stipulated by the culture of this group. If someone that is not Floral-belt Dai sees it, he or she may not understand its meaning.

For someone from a foreign culture, the first, second, and third behaviors still need explaining, but the structures of explanation are different. There is only one declarative sentence for the explanations of the second and third behaviors. Its meaning is direct, not transferred, symbolic, or metaphoric. When this explanation was made, the one who explained and the one who was explained to were both clear about it, and there was no need to talk further. In other words, the explanations for the second and third activities had only one step and just stopped there, whether for natives or researchers. After Dao said tying the cricket with a thread was to prevent it from being taken away by the wasp and tying the down was to mark and help us to catch up with the wasp, the explanation ended and the cause and effect became obvious. ${ }^{30}$ Behaviors like tying a white feather to the wasp's waist could easily be mistaken for symbols, but when the native gives the reason it is clear to all that it has nothing to do with symbols.

However, the explanation for the first activity is far from complete. Instead, further explanation must be made, whether for researchers or for natives. When hearing the explanation that the witch was calling heng, and that chanting and behaviors like swinging the sickle and dropping the wood strips were to call the 
heng of wasps back, researchers will probably query further and the informant will explain additionally: "Heng is owned by every living thing. Living things can flourish only with adequate heng. Heng will constantly disperse. The hive collector's harvest was not good before because the heng was not sufficient. Through calling heng the dispersed heng will return. Hunters will get more and better quarries when the heng of the wasps is abundant." In my fieldwork the old Floral-belt Dai did make such an explanation. Only with the above three explanations can an answer to the puzzling first behavior be made complete for me as an observer.

\section{Conclusions}

Thus a further definition of rituals is that they are patterned human activities with deep cultural meaning, and each cultural group stipulates this distinct meaning. Cultural meanings of different ethnic groups may be quite different. Therefore, activities that an observer from a foreign culture is not able to understand are considered rituals only when they have "progressive meanings" or "symbols." 31 To put it plainly, when you go to a society of others to conduct fieldwork, you encounter activities that you do not understand and have to ask about, and must ask further to complete the explanation. These are rituals.

Now we can be sure that cultural meanings are the core element of rituals. Making a definition for rituals is not merely to distinguish rituals from other types of activities. Like the above scholars, our purpose of definition is to facilitate our research. In fact, how to define a concept implies how to research this social phenomenon. That is, a definition actually demonstrates the approach of research, that is, its methodology. This is not difficult to see in definitions of rituals by functionalism, structuralism, symbolism, and interpretivism. That is also our aim of making a definition from the epistemology perspective today.

Therefore, the first and foremost task of ritual study is to master the meanings of every symbol and metaphor through deep interviews after participatory observation. If there is "progressive meaning," it needs researchers to master it and trace the explanations till no further explanation can be made. Through tracing the meanings of an ethnic group's various rituals, researchers may find that ultimate explanations always point to a small number of propositions. For example, in Floral-belt Dai society I recorded dozens of types of rituals, which can be divided into therapeutic rituals, harvest rituals, fertility rituals, funeral rituals, and so on in terms of functionalism, or periodic fixed rituals and occasional rituals in terms of regularity. Although the presentations are diverse, their cultural explanations can be traced back to the three laws of heng mentioned above ${ }^{32}$ whereas in The Age of Wild Ghosts, Mueggler only uses a few core principles such as "orderly flow" and "powerful outsiders" to explain Yi's seemingly crazy activities. ${ }^{33}$

These few propositions are believed and obeyed by the entire ethnic group. Their various behaviors, rituals included, are arranged according to these few propositions; their various social rules all stem from them as well. According to theories put forward by Professor Hua Cai in his Man Thought by Man (Ren Si Zhi Ren), ${ }^{34}$ such a proposition is called "belief." In the society as a whole, people behave according to their beliefs. The "cultural facts" it represents is the basis of the consturction of "social facts." 
That is to say, the exploration into "cultural facts" is the core of ritual study and all anthropological fieldwork. After determining the belief systems (i.e., cultural facts) of the ethnic group through research, scholars can still do research based on meaning, such as structuralism cross-cultural comparison, phenomenology, and semiotics discussion, but getting the "cultural facts" of the objects of study is the prerequisite for all the subsequent research. This is the first and foremost task for ritual study or even all other anthropological research.

Until now we could take the "further explanation structure" as the structural feature of ritual, and could regard the derivation from notion to behavior from epistemological angle as the logic of ritual activities. Upon these two conclusions, we can explore the function and representation of ritual. A society's cultural facts, or to say basic propositions that are generally accepted, exist in human concepts. Concepts are invisible in themselves. For example, according to the ancient Greeks' body representation system, people believed a man's sperm and a woman's menstrual blood coagulated into a fetus, but the process was invisible. In the Floral-belt Dai's religious concept, as the source of all life, heng's dispersion and return result in two forms of life, sickness and health. This process is invisible as well. However, they are represented as visible actions through rituals. Body representation concepts are invisible, but the ritual of "consanguineous alteration" 35 held for a consanguineous marriage $\mathrm{e}^{36}$ is visible; the dispersion and return of heng are invisible, but rituals of calling heng and maintaining heng are visible. Rituals are not only literally visible through the eyes, but also sensible through other sensorium. For example, sounds (like chanting), touch (like baptism), smell (like burning incense), and even taste (like hallucinogenic mushrooms) are included in many rituals. That is, all rituals are reflected in human sense organs. We say rituals are "visible" because vision is the most intuitional and strongest of the human senses.

On the other hand, concepts are static while rituals are manifestations of motion. Cultural facts can usually be presented as a declarative sentence or an assertion. They do not contain imperative actions. One example is the Ao Yao's concept that illness is caused by the gods and ghosts who take the patients' spirits to blackmail them for food. Rituals are procedural human behaviors. Any ritual has a clearly prescribed process of actions. For example, the Ao Yao's treatment ritual can be formulated as "cook a meal and pour wine, touch the infected part of the patient, chant to send agents to negotiate with the gods, then offer the oblations to the gods' place and take the patient's spirits back." People who participate in the ritual undertake such processes with bodily and oral actions. That is the ritual's "actability." Visibility and actability make the ritual effective for participants to learn and repeat it. Newcomers can acquire the ritual from the veterans through procedures. Thus rituals are passed on within the ethnic group and over generations, carrying the concepts with them.

In contrast, culture facts can never maintain their social existence in the form of invisible and static concepts, nor can they be disseminated through society in that form. Culture facts must be embodied as visible and activate behaviors to be transmitted vertically and horizontally. If we admit that human beings are dependent on cultural meanings, then the visible and activated embodiment of cultural concepts is a universal need for all human societies, both pr-industrial 
and the modern ones. The National Day Ceremony of modern societies is the same in structure and function with the heng summoning ritual of the Flora-belt Dai. The collective effervescence of Moon Mistresses is the same as a golden wedding anniversary. This is why rituals are so common in all societies-life needs the sense of ritual.

\section{Endnotes}

${ }^{1}$ Journal of Ritual Studies in English, America, for example. In recent years, journals in Chinese such as Newsletter of Chinese Ritual Studies have also come out.

2"Floral-belt Dai" is an ethnic group living in central Yunnan Province with a population of over 80,000 and several branches. Traditionally, it is an agricultural group that cultivates rice in paddy fields as its main livelihood. From 2006 to 2007, I conducted fieldwork for a year and 2 months in the Floral-belt community. I became fluent in their language, did participatory observation, conducted interviews, and took photographs of their rituals. Like other agricultural ethnic groups, they have a large number of rituals related to fertility.

${ }^{3}$ In Dai, "p "i1" is transliterated as "pea." It roughly means the collection of gods, spirits, and ghosts.

${ }^{4}$ Pronouced "xen" in Dai and transliterated as heng.

${ }^{5}$ After each chanting, the Floral-belt Dai will toss the pair of wood or bamboo strips until they get a satisfactory result, i.e., the divinatory symbols are one positive and one negative.

${ }^{6}$ It is the Floral-belt Dai's custom that no one is allowed to work in the fields during the Spring Festival. After the festival, they select a lucky day and kaiyangmen under the direction of shetou. The villagers fire the pistol, light the joss stick, and walk out the village gate. On the day of kaiyangmen, everyone goes to the fields. After kaiyangmen, the villagers resume agricultural production and daily life.

${ }^{7}$ In some cases, people with supereyes are able to see heng.

${ }^{8}$ In the ritual, the head witch of the village claims to be possessed by these $\mathrm{p}^{\text {' } \mathrm{i} \text {, and }}$ the words that she speaks are from $\mathrm{p}^{\text {‘ } \mathrm{i} \text {. }}$

${ }^{9}$ Pronounced ja」 mwen kwan van」 in Dai. The witches are women who can communicate with p i $i$ and the clergy of Floral-belt Dai. There are many witches in a village, but only one is in charge of the collective rituals held in the village, i.e., the head witch of the village.

${ }^{10}$ See the details of this ritual in my essay "The Social Structure and the Rites of Passage" in Ethno-National Studies, 6th volume, 2012.

${ }^{11}$ The Floral-belt Dai have a language but no characters. As mentioned above, I learned their language.

${ }^{12}$ Pronounced mwen in Dai. This is a noun often used as the object in verb-object phrases or an attribute to modify nouns.

${ }^{13}$ Quoted from Oxford English Dictionary.

${ }^{14}$ This was the answer given by a Floral-belt Dai when I asked what kind of people could undertake the ritual of calling heng.

${ }^{15}$ The Aoyao are a branch of the Yao and live in the Dayao Mountain area, Jinxiu County, Guangxi Province. The group has a population of over 7000. Traditionally, the Tao make a living mainly by rice planting as well as hunting. In February and May 2013, I twice went to villages inhabited by Aoyao to conduct fieldwork. 
${ }^{16}$ A wizard is a clergy of Aoyao called "Shi Gong." Wizards mentor apprentices with scriptures in which Aoyao incantations were recorded by their pronunciation in Han characters. Aoyao wizards have their inauguration called "Du Jie."

${ }^{17}$ Quite different from the circumstances of the Floral-belt Dai, due to the limited time, I had not learned the Aoyao's language. This interview with the wizard was conducted in Mandarin. Due to the barrier of nonmother-tongue expressions, some core concepts like souls, cold, or hot may not be exact. Here, I just quote his general ideas.

${ }^{18}$ As stated before, I was not fluent in the Yao's language. This conversation was in Mandarin. The word "sacred" was also in Mandarin.

${ }^{19}$ See the case in my book, Qiao Wu (2011). The Cosmology and Life-World. China Social Sciences Press: 291.

${ }^{20}$ See a case in my book The Cosmology and Life-world. An old Floral-belt Dai woman held rice tightly in her hands and stroked her traditional costumes in the ritual of asking p'i1. The expressions, words, and gestures were so ordinary that at first I did not realize it was a ritual at all.

${ }^{21}$ Turner uses the term "metaphor" as basically equivalent to "symbol," but when other anthropologists use this term it is a little different. Metaphors mainly refer to rhetoric (vocabulary) in language, whereas symbols mainly refer to other nonverbal "signifiers" like shapes, actions, and things.

${ }^{22}$ Kapok is also known as Bombax ceiba. It is a perennial tree that blossoms in spring and its fruit matures in summer. Some ethnic groups in South China use white velvety fiber inside the fruit shells to spin, weave, and make clothes. Such plant fiber is a material as common as cotton and flax.

${ }^{23}$ Traditionally, chicken, geese, and ducks all graze in the Floral-belt Dai area. Geese and ducks go out of the home at dawn every day and go to paddy fields as well as streams to get food. Chickens get their food from the grass on the hillside. At dusk, the housewives make the sound "dodo" and scatter rice to lure the fowl back home. Newborn geese and ducks need to be driven back, but they soon return by themselves once they hear the sound.

${ }^{24}$ This is an answer to my question "What on earth is calling heng?" to a witch in Buffalo village.

${ }^{25}$ Jan A.M. Snoek, 2006.

${ }^{26}$ The characteristics he lists go against traditional principles of classification in terms of sorting technique: classifications within one category and one level should never overlap each other. For example, seven of the characteristics Snoek lists are actually of the same class: culturally constructed, traditionally sanctioned; prescribed, having a script; formal(ized), conventional; structured, patterned, ordered, sequenced, rule-governed; standardized; rigid, stereotyped, stable; repeated, repetitive, and taking places at specific places and/or times.

${ }^{27}$ According to Article 3 in the United Nations Convention on the Law of the Sea enacted in 1982, every state has the right to establish the breadth of its territorial sea up to a limit not exceeding 12 nautical miles, measured from baselines. In practice, the breadth of most coastal states' territorial sea is 12 nautical miles. There are also a few states that take different rules. Hugo Grotius, an international law scholar in seventeenth-century Holland, proposed that if people who sailing on an area of the sea could be constrained by coercive power from the land, then such an area belongs to 
this land. In other words, the sea area in charge of a country depends on the effective control over it (Wikipedia, "name of article").

${ }^{28}$ Wasps are large gregarious insects that feed on meat. The Floral-belt Dai have enjoyed their larvae and pupa as food since ancient times.

${ }^{29}$ As has been stated before, calling heng can usually be conducted by any housewife, but the Floral-belt Dai still believe an experienced witch's calling is more effective. Thus Dao did not ask his wife to call heng for him but Meizhen Bai in the same village.

${ }^{30}$ Max Weber in "Economy and Society: An Outline of Interpretive Sociology" and Geertz in "The Interpretation of Culture" both distinguish "interpretation" and "explanation." The relation of cause and effect needs to be explained while the meaning of culture needs interpretation. Here, the two explanations are simply for a cause-and-effect relation with no cultural meanings. This opinion was indicated by Professor Hongguang Luo in an oral conversation.

${ }^{31}$ In fact, symbols can be regarded as a kind of progressive meanings. That is, the correspondence between symbols and the symbolized must be explained. For example, when I asked the Floral-belt Dai why white was the symbol of grieving, they explained that white was the original color of kapok. People at a funeral were grieving so deeply for relatives' death that they were in no mood to dress up and dye the cloth. That was why wearing clothes in its original color represented grief. When I asked the Aoyao wizard why red symbolized sacredness, he explained that red was the brightest color so it was used to represent spirits. However, further explanations for symbolic meanings are usually unknown to most people in this culture. They are simply used to the existence of such a correspondence. For example, the above two explanations are not known to all Floral-belt Dai and Aoyao people.

${ }^{32}$ In the case of the Floral-belt Dai, the three laws of heng as well as a few rules of $\mathrm{p}^{\text {‘ } \mathrm{i}}$ constitute the logic origin of all rituals concerning religion within this ethnic group. Due

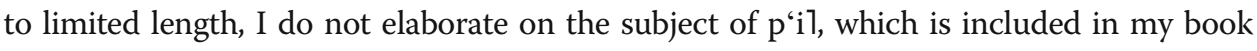
The Cosmology and Life-world.

${ }^{33}$ About the analysis of basic propositions in Mueggler's "The Age of Wild Ghosts," see my "Perception of Anthropologists, Understanding of Philosophers, and Speaking of Literatures-a Commentary" of "The Age of Wild Ghosts" in "Journal of Xinjiang Normal University (Social Science)", 2nd Volume, 2008.

${ }^{34}$ See Hua Cai (2009), Ren Si Zhi Ren (Man Pondered by Man), Kunming: Yunnan People's Publishing House.

${ }^{35}$ Han (2009), A Tree Without Annual Ring by, Kunming: Yunnan People's Publishing House.

${ }^{36}$ Junkui Han describes a ritual among the Lahu people in Yunnan: when a man and a woman are not aware that they are distantly consanguineous until after they have married, the ritual of "consanguineous alteration" will be held to transfer one of them to the other's nonconsanguineous social group so that the marriage will become lawful. 


\section{Publisher's Note}

Springer Nature remains neutral with regard to jurisdictional claims in published maps and institutional affiliations.

Received: 4 April 2018 Accepted: 20 July 2018

Published online: 23 August 2018

\section{References}

Bocock, R. 1974. Ritual in industrial society: a social analysis of ritualism in modern England. London: George Allen \& Unwin.

Cai, Hua. 2009. Ren Si Zhi Ren (Man Thought by Man). Kunming: Yunnan People's Publishing House.

Delattre, R. 1978. Ritual resourcefulness and cultural pluralism. Soundings 61(3):281-302.

Durkheim, Emile. 1999. The elementary forms of the religious life, trans. Qu Dong and Ji Zhe. Shanghai: Shanghai People's Publishing House.

Firth, R. 1951. Elements of social organisation. London: Watts \& Co.

Geertz, Clifford. 1973. The interpretation of cultures: selected Essays. New York: Basic Books.

Han, Junkui. 2009. A tree without annual ring. Kunming: Yunnan People's Publishing House.

Jan, A.M. Snoek. 2006. Defining Rituals. In Theorizing Rituals, Issues, Topics, Approaches, Concepts, ed. by Jens Kreinath, Jan Snoek and Michael Stausberg, 3-14. Leiden/Boston: Brill.

Kertzer, D. I. 1988. Ritual, politics, and power. New Haven, CT: Yale University Press.

Leach, E. R. 2004. Political systems of highland Burma: a study of kachin social structure. London: The Athlone Press.

Platvoet, J. G. and K. Van Der Toorn, eds. 1995. Pluralism and identity: studies in ritual behaviour, vol. 67. Leiden: Brill.

Tambiah, S. J. 1979. A performative approach to ritual. Proceedings of the British Academy 65: 113-169.

Turner, V. W. 1967. The forest of symbols: aspects of Ndembu ritual, vol. 101. Ithaca, NY: Cornell University Press.

Wu, Qiao, The Cosmology and Life-world, Beijing: China Social Sciences Press, 2011.

\section{Submit your manuscript to a SpringerOpen ${ }^{\circ}$ journal and benefit from:}

- Convenient online submission

- Rigorous peer review

- Open access: articles freely available online

High visibility within the field

- Retaining the copyright to your article 